\title{
Effect of modified dairy fat on fasting and postprandial haemostatic variables in healthy young men
}

\author{
Tine Tholstrup ${ }^{1}$, Peter Marckmann ${ }^{1}$, John Hermansen ${ }^{2}$, Gunhild Hølmer ${ }^{3}$ and Brittmarie Sandström ${ }^{1}$ \\ ${ }^{1}$ Research Department of Human Nutrition, Center of Advanced Food Research, \\ Royal Veterinary and Agricultural University, Frederiksberg, Denmark \\ ${ }^{2}$ Department of Product Quality, Danish Institute of Animal Science, Foulum, Denmark \\ ${ }^{3}$ Department of Biochemistry and Nutrition, Technical University of Denmark, Lyngby, Denmark
}

(Received 23 January 1998 - Revised 7 December 1998 - Accepted 22 March 1999)

\begin{abstract}
It has been suggested that milk fat, due to its content of saturated fatty acids, may have a thrombogenic effect. In the present study the fatty acid profile of milk fat was modified by changing the feeding regimens of cows and the effect on haemostatic variables of a diet containing the modified milk fat (M) was compared with that of a diet containing milk fat of typical Danish composition (D). In the modified fat $16 \%$ of the saturated fatty acid $\left(\mathrm{C}_{12}-\mathrm{C}_{16}\right)$ content was replaced mainly by oleic acid. Eighteen subjects were fed on two strictly controlled isoenergetic diets containing $40 \%$ energy from total fat (30\% energy from the test fats) for periods of 4 weeks in a study with a crossover design. Fasting samples were taken in the last week of each study period. Postprandial samples were taken on day $21,3 \mathrm{~h}$ after lunch $(n 18)$, and on the last day of the study 2, 4, 6 and $8 \mathrm{~h}$ after a fat load containing $1.2 \mathrm{~g}$ of one of the milk fats $/ \mathrm{kg}$ body weight $(n 8)$. After 4 weeks' dietary intervention fasting plasma factor VII coagulant (FVIIc) activity, tissue-type plasminogen activator (t-PA) activity, plasminogen activator inhibitor (PAI-1) antigen and $\beta$-thromboglobulin did not differ between diets M and D. Postprandially FVIIc and t-PA activities increased $(P<0.001)$ and PAI- 1 antigen and PAI- 1 activity decreased $(P<0.001)$ as compared with fasting values, regardless of diet. After the fat load, the postprandial increase in FVIIc was marginally lower after diet $\mathrm{M}$ than diet $\mathrm{D}$ (diet effect, $P<0.05$ ). In conclusion, the modified milk fat obtained by the applied feeding strategy had virtually the same effects on haemostatic variables as conventional milk fat.
\end{abstract}

Milk fat: Haemostasis: Fatty acids

Dairy products, which comprise a considerable proportion of the diet in Northern Europe and the USA, contain important nutrients such as protein of high quality, vitamins, $\mathrm{Ca}$ and $\mathrm{Zn}$. Nevertheless a nutritional disadvantage of dairy fat is its high content of saturated cholesterolaemic fatty acids. A thrombogenic effect of a diet rich in saturated fatty acids has been suggested as well (Connor \& Poole, 1961; Connor, 1962; Botti \& Ratnoff, 1963; Nordøy \& Goodnight, 1990). However, the fatty acid composition of milk can be changed by dairy herd feeding procedures.

Most of the studies of the effects of saturated fatty acids have monitored changes under fasting conditions. Human beings spend most of their lives in a postprandial state in which plasma triacylglycerol concentration is elevated as a consequence of intake of dietary fat. There is growing epidemiological, clinical and experimental evidence that hypertriacylglycerolaemia may represent a procoagulant state (Silveira et al. 1994), and that fatty meals result in postprandial elevation of plasma factor VII (FVII) coagulant (FVIIc) activity (Bladbjerg et al. 1994; Silveira et al. 1994; Miller et al. 1996). FVII is a key protein of the haemostatic cascade. FVIIc was found to be an independent risk factor for coronary events in middle-aged men in the Northwick Park Heart Study (Meade et al. 1993). In an 8-year follow up of the PROCAM study, FVIIc was also associated with risk of CHD, although not independently (Junker et al. 1997).

From the present study we have previously reported the effect of two milk fats, produced by different cow-feeding regimens, on blood lipids and lipoproteins in healthy young men. We observed that milk fat with a higher content of oleic acid caused higher fasting and postprandial plasma triacylglycerol concentrations than milk fat with a fatty acid composition corresponding to conventional Danish milk fat

\footnotetext{
Abbreviations: diet D, diet containing conventional Danish milk fat; diet M, diet containing modified milk fat; FVIIc, factor VII coagulant; PAI-1, plasminogen activator inhibitor type 1; t-PA, tissue-type plasminogen activator.

* Corresponding author: Dr Tine Tholstrup, fax +45 3528 2469, email TineTholstrup@fhe.kvl.dk
} 
(Tholstrup et al. 1998). In the present paper the effects on selected haemostatic variables, including FVIIc, are presented. The milk fat was modified by means of realistic, cost-neutral changes to the feed composition of the dairy herd and resulted in a partial replacement of palmitic acid (and to a lesser extent myristic acid) with oleic acid (and to a lesser extent stearic acid). Based on earlier observations (Tholstrup et al. 1994a), we hypothesized that the modified milk fat might be associated with lower FVIIc levels.

\section{Methods \\ Subjects}

Eighteen young men were recruited for the study. Their ages ranged from 21 to 28 years (mean 25 years), body weights ranged from 63 to $104 \mathrm{~kg}$ (mean $80 \mathrm{~kg}$ ), and BMI from 19 to $27 \mathrm{~kg} / \mathrm{m}^{2}$ (mean $24 \mathrm{~kg} / \mathrm{m}^{2}$ ). The subjects had no history of atherosclerotic disease and all were apparently healthy as assessed by a medical questionnaire. They were all nonsmokers and were not taking any medication. Most subjects had a moderate physical activity level (training maximum 1-2h twice weekly and/or daily cycling to work). They continued with the same physical activity throughout the trial. Two different diets were served in randomized order for 4 weeks each. The two intervention periods were separated by a 2-month period on habitual diet.

The participants' habitual diets were assessed from $7 d$ weighed food records. We calculated energy intake and nutrient composition using a national database (Dankost, National Food Agency, Denmark). Habitual energy intakes ranged from 9 to $19 \mathrm{MJ} / \mathrm{d}$ (mean $14 \mathrm{MJ} / \mathrm{d}$ ) with $26-42 \%$ energy from fat (mean $32 \%$ energy), the polyunsaturated fatty acid: saturated fatty acid ratio was $0 \cdot 2-0 \cdot 8$ (mean 0.4 ); intake of cholesterol was $175-665 \mathrm{mg} / 10 \mathrm{MJ}$ (mean $371 \mathrm{mg} / 10 \mathrm{MJ})$, and dietary fibre intake ranged from 1.4 to $3 \cdot 2 \mathrm{~g} / \mathrm{MJ}$ (mean $2 \cdot 4 \mathrm{~g} / \mathrm{MJ}$ ).

\section{Milk fat production}

Two different types of milk were produced at the Danish Institute of Animal Science. Forty cows were given a basal diet ad libitum (mixture of beets, grass silage, crushed barley and straw) and supplemented with two different concentrate mixtures. Using the prediction formulas of Hermansen (1995) the two concentrate mixtures were composed in such a way that they were expected to result in either a normal milk fat composition or in a milk fat high in oleic acid. The normal concentrate mixture consisted of $940 \mathrm{~g}$ soyabean meal $/ \mathrm{kg}$ and $60 \mathrm{~g}$ saturated fats $/ \mathrm{kg}$ and was given at a level of $4.7 \mathrm{~kg} / \mathrm{cow}$ per $\mathrm{d}$. The experimental concentrate consisted of $500 \mathrm{~g}$ soyabean meal $/ \mathrm{kg}$ and $500 \mathrm{~g}$ crushed double-low rapeseeds/kg (low in glucosinates and erucic acid) given at a level of $3 \cdot 2 \mathrm{~kg} / \mathrm{cow}$ per d. After 3 weeks of feeding with the normal concentrate, milk was collected for production of conventional butter, high in palmitic acid. Subsequently, the cows were given the experimental concentrate for a period of 7 weeks after which milk was collected for production of the modified butter, high in oleic acid. The fatty acid compositions of
Table 1. Fatty acid compositions of ( $\mathrm{g} / 100 \mathrm{~g}$ total fatty acids) of the two test milk fats as analysed by GLC

\begin{tabular}{lcc}
\hline Fatty acid & Modified milk fat $(\mathrm{M})$ & Danish milk fat (D) \\
\hline $4: 0$ & 3.46 & 3.83 \\
$6: 0$ & 1.88 & 2.34 \\
$8: 0$ & 1.08 & 1.40 \\
$10: 0$ & 2.30 & 3.14 \\
$10: 1$ & 0.22 & 0.37 \\
$12: 0$ & 2.86 & 4.09 \\
$14: 0$ & 10.67 & 12.07 \\
$14: 1$ & 1.83 & 1.81 \\
$15: 0^{*}$ & 1.01 & 1.45 \\
$16: 0^{*}$ & 21.13 & 36.82 \\
$16: 1 n-7$ & 1.71 & 2.25 \\
$17: 0^{*}$ & 0.89 & 1.17 \\
$17: 1$ & 0.24 & 0.31 \\
$18: 0$ & 10.88 & 7.23 \\
$18: 1$, trans & $6.4 \ddagger$ & $1.1 \S$ \\
$18: 1 n-9$ & 24.95 & 15.33 \\
$18: 1 n-7$ & 1.40 & 0.55 \\
$18: 2 n-6$ & 1.93 & 1.61 \\
$20: 0$ & 0.22 & 0.14 \\
$18: 3 n-3$ & 0.50 & 0.42 \\
Conjugated 18:2† & 1.57 & 0.52 \\
\hline
\end{tabular}

${ }^{*} 15: 0,16: 0$ and 17:0 also included the branched isoforms typical of milk fat. † Conjugated 18:2 also included 20:0 (0.20-0.25 g/100 g total fatty acids).

$\ddagger$ The two major trans isomers were $18: 1 n-7$ and $18: 1 n-8$, about $2 \mathrm{~g} / 100 \mathrm{~g}$ total fatty acids of each.

$\S$ The major trans isomer was 18:1n-7.

conventional and modified butters were determined by GLC as described by Bysted et al. (1998) (Table 1).

\section{Human diets}

We served two diets, one high in conventional Danish butter (diet D), and one in which the modified butter replaced the conventional butter (diet M). Energy intake was individualized based on the food records of the subjects, taking body weight, sex, age, and level of physical activity into account (World Health Organization, 1985).

Both human experimental diets contained $40 \%$ energy as fat; $30 \%$ energy came from butter, $6.5 \%$ energy from grapeseed oil, and the remaining fat content of $3.5 \%$ energy from other food items, which were constant and identical in the two test diets. The experimental meals consisted of natural and common food items, which were prepared and cooked in customary ways. The two butters were served as spread and incorporated into bread, rolls and cakes. Dinner dishes consisted of cooked vegetables and lean meat with pasta, rice or mashed potatoes. Grapeseed oil was included in the dinner dishes in order to get a more balanced fatty acid composition. Bread rolls, marmalade, orange juice and tea or coffee were served for breakfast. Lunch was a cold meal consisting of lean roast beef or fish paté and salad dressing without fat. Fruit juice, fresh fruit, cakes and candies were served as snacks. Pooled duplicate portions of 1 week of each test diet were collected and analysed by the National Food Agency of Denmark (Table 2). Additional details of fatty acid composition of the test diet in the study are presented elsewhere (Tholstrup et al. 1998).

All foods were prepared and weighed in individual 
Table 2. Analysed mean daily energy content and nutrient composition of the experimental diets containing modified milk fat (M) or conventional Danish milk fat (D)*

\begin{tabular}{ccc}
\hline & Diet M & Diet D \\
\hline Protein (g/10 MJ) & 68 & 66 \\
$(\%$ energy) & 11.6 & 11.3 \\
Carbohydrate (g/10 MJ) & 281 & 283 \\
$(\%$ energy) & 47.7 & 49.2 \\
Total fat (g/10 MJ) & 107 & 107 \\
$(\%$ energy) & 40.5 & 41.5 \\
Cholesterol (mg/10 MJ) & 373 & 386 \\
\hline
\end{tabular}

*Analysed values are means of two duplicate portions. Variations between periods were negligible. There was good agreement between analysed and calculated values (results not shown).

servings in the experimental kitchen of the Research Department of Human Nutrition of the Royal Veterinary and Agricultural University. Lunch was served on weekdays at the Department. All other dishes were provided daily as a package with instructions for preparation. Meals for the weekend were provided on Fridays. Body weight without heavy clothing was recorded before lunch three times weekly. Physical activity was restricted and daily records of tea and coffee intake were kept. Physical activity, illness and deviation from the protocol were monitored as described earlier (Tholstrup et al. 1994a).

On the last day of each 4-week experimental period the effect of a fat load was investigated in a subgroup of eight individuals. The fat-load meal consisted of bread rolls and cake enriched with either of the two butters (the same as was eaten during the preceding 4 weeks), orange juice and marmalade. The fat content of the test meal was fixed at $1.2 \mathrm{~g}$ milk fat $/ \mathrm{kg}$ body weight. Of the energy, $56 \%$ was derived from fat, $41 \%$ from carbohydrates, and $4 \%$ from protein. The energy content of the test meals ranged from $5.7 \mathrm{MJ}$ to $8.7 \mathrm{MJ}$ (mean 6.7 MJ) and the content of fat in each test ranged from $83 \mathrm{~g}$ to $126 \mathrm{~g}$ (mean $98 \mathrm{~g}$ ).

\section{Blood analysis}

Blood samples were taken by venepuncture with minimum stasis and collected into siliconized vacutainers. Subjects refrained from heavy physical activity or alcohol intake for at least $24 \mathrm{~h}$, fasted for at least $12 \mathrm{~h}$, and rested supine for 15 min before sampling.

Fasting samples for analysis of FVIIc, fibrinolysis variables, and $\beta$-thromboglobulin were taken before and on days 21 and 28 of each experimental period. On day 21, nonfasting blood samples were drawn from all subjects $3 \mathrm{~h}$ after lunch. On day 28 , a subgroup of eight volunteers consumed a fat-load meal in the morning and had blood samples taken at 2, 4, 6 and $8 \mathrm{~h}$ after the meal. Blood for lipid analysis was collected in tubes containing EDTA, and was immediately placed on ice and centrifuged at $3000 \mathrm{~g}$ for $15 \mathrm{~min}$ at $4^{\circ}$. Plasma for fatty acid analysis was stored at $-80^{\circ}$. Plasma triacylglycerol concentration was assessed by enzymic procedures (Boehringer Mannheim $\mathrm{GmbH}$, Mannheim, Germany) on a Cobas Mira analyser (Roche, Basal, Switzerland). Blood for FVIIc and fibrinogen determinations was collected in citrated tubes (kept at room temperature for not more than $1 \mathrm{~h}$ ), and that for fibrinolytic variables was collected into pre-cooled tubes containing strong acidic citrate (Stabilyte, Biopool, Umeå, Sweden). All samples were spun for $15 \mathrm{~min}$ at $3000 \mathrm{~g}$ (samples for fibrinolysis at $4^{\circ}$, the others at room temperature). The separated plasma was pipetted into plastic vials and then rapidly frozen and stored at $-80^{\circ}$. Additional details have been described previously (Marckmann et al. 1992b). Plasma FVIIc (\%) was assessed in a one-stage clotting assay as described by Thomson (1985). After incubation of $100 \mu$ l diluted test plasma (1:10 in TRIS-buffer) and $100 \mu$ l human FVIIdeficient plasma (Biopool) at $37^{\circ}$ for 3 min the clotting process was initiated by addition of $200 \mu \mathrm{l}$ of a mixture of $25 \mathrm{mM}-\mathrm{CaCl}_{2}$ solution and human thromboplastin $(1: 1$, $\mathrm{v} / \mathrm{v})$. The clotting time was recorded on a coagulometer (Schnittger-Gross, Amelung, Germany), and FVIIc expressed relative to a commercial reference plasma (Haemostasis Reference Plasma, Biopool: assayed value 106 (range 90122) \%). Plasma tissue-type plasminogen activator (t-PA) activity $(\mathrm{mIU} / \mathrm{ml})$ and plasminogen activator inhibitor type 1 (PAI-1) antigen concentrations ( $\mathrm{ng} / \mathrm{ml}$ ) were assessed by commercial ELISA (Biopool). Plasma PAI-1 activity was estimated by a chromogenic assay (Spectrolyse/pL PAI, Biopool) (Gram et al. 1993). Plasma fibrinogen ( $\mu \mathrm{mol} / \mathrm{l})$ was determined by a functional assay (Marckmann et al. 1991). At each blood sampling, blood for $\beta$-thromboglobulin analysis was always collected in the second tube (Diatube H tubes, Diagnostica Stago, Asnieres sur Seine, France), containing an anticoagulant mixture with the vacuum already broken. Plasma $\beta$-thromboglobulin was assessed by a commercial enzyme immunoassay kit (Asserachrom kit, Diagnostica Stago). For a further description, see Takahashi et al. (1988). Six single samples (out of $246)$, which were clear outliers $(>60 \mathrm{IU} / \mathrm{ml})$ compared with the normal range of $\beta$-thromboglobulin in the particular subject, were excluded. High values $>60 \mathrm{IU} / \mathrm{ml}$ indicate ex vivo release of $\beta$-thromboglobulin. We did not observe the same outlier pattern in the PAI-1 samples, for which reason none of the PAI-1 samples was excluded.

Fatty acid compositions of plasma triacylglycerol samples were determined in samples taken before and 2, 4, 6, and $8 \mathrm{~h}$ after the fat load $(n 8)$. The plasma lipids were extracted into chloroform-methanol $(1: 1, \mathrm{v} / \mathrm{v})$ and the phospholipids and cholesterol esters were separated by TLC on precoated silica gel 60 plates (Merck, Darmstadt, Germany) with hexane-diethylether-acetic acid $(80: 20: 1$, by vol.) as the mobile phase. Methyl esters were prepared by transmethylation catalysed by $\mathrm{BF}_{3}$ (Høy \& Hølmer, 1988). The fatty acid composition was determined by GC using a HP5880A instrument with split injection and a $30 \mathrm{~m} \times$ $0.32 \mathrm{~mm}$ fused silica column with a $0.2 \mu \mathrm{m}$ film of SP2380 (Supelco Inc., Bellafonte, PA, USA). The oven was programmed to increase the temperature at a rate of $2 \% \mathrm{~min}$ from $140^{\circ}$ to $160^{\circ}$ and after $2 \mathrm{~min}$ to $200^{\circ}$ at $3 \% \mathrm{~min}$. The fatty acids were identified by comparing retention times with those of standards of fatty methyl esters.

\section{Ethics}

The protocol and the aim of the study were fully explained to the subjects, who gave their written consent. The research 
protocol was approved by the Scientific Ethics Committee of the municipalities of Copenhagen and Frederiksberg (01-487/93).

\section{Statistical analysis}

The effect of the experimental diet on fasting haemostatic variables was compared by Wilcoxon's matched-pairs signed-rank test. Our study had the power of $80 \%$ to detect differences in fasting plasma FVIIc of approximately $4 \%$ between diets $(n 18, \alpha 0 \cdot 05$, SD intra-individual FVIIc variation on fixed diets $4 \%$, calculated on basis of unpublished data from an earlier dietary study). We have no access to data that could be used for precise power calculations with respect to non-fasting FVIIc, but we estimate it was slightly smaller as compared with fasting FVIIc. To analyse postprandial data repeated measures ANOVA (SPSS Inc., Chicago, IL, USA) with Huynh-Feldt adjustment of degrees of freedom was used to assess effect of time, difference in effect of the experimental fats, and interaction between effects of time and type of fat during the day.

\section{Results}

The modified milk fat $(\mathrm{M})$ obtained by the new feeding strategy had a lower content of $\mathrm{C}_{12}-\mathrm{C}_{16}$ fatty acids (from 53 to $35 \mathrm{~g} / 100 \mathrm{~g}$ fat), and a higher content of $18: 0+18: 1 n-9$ (from 23 to $36 \mathrm{~g} / 100 \mathrm{~g}$ fat) as compared with the conventional fat (D). In addition it had, unexpectedly, a sixfold higher trans fatty acid content $(18: 1 n-7+18: 1 n-8)$ and a threefold higher conjugated linoleic acid content (Table 1).

\section{Effect of 4 weeks' intake of experimental diets (n 18)}

There were no significant differences between diets D and $\mathrm{M}$ for any haemostatic variable in fasting samples collected after 4 weeks (Table 3 ).

\section{Effect of 3 weeks' intake of experimental diets (n 18)}

There was no significant difference (diet $\times$ time interaction) between diets $\mathrm{D}$ and $\mathrm{M}$ for fasting and non-fasting ( $3 \mathrm{~h}$ after lunch) levels of the measured haemostatic variables. Plasma FVIIc and t-PA activity increased and PAI-1 antigen decreased significantly from morning to afternoon (time effect, $P<0 \cdot 001$ ) on both diets, but no diurnal fluctuations were seen for $\beta$-thromboglobulin (data for FVIIc and total triacylglycerol only shown in Fig. 1).

\section{Effect of a fat load on day 28 (n 8)}

For both diets, a diurnal increase in FVIIc and t-PA activities (time effect, $P<0.001$ ) and a decrease in PAI-1 activity (time effect, $P<0 \cdot 001$ ) were seen (Fig. 2). Postprandial FVIIc levels were marginally lower after diet $\mathrm{M}$ as compared with diet D (diet effect, $P<0.05$ ). Since baseline levels of $\beta$-thromboglobulin tended to differ, although not significantly, the changes ( $\Delta$-values) from the initial value at $0 \mathrm{~h}$ were analysed. The $\Delta$-values for $\beta$-thromboglobulin varied over the day (time effect, $P<0 \cdot 01$ ). Fig. 1(d) shows an increase after diet $\mathrm{D}$ and a slight decrease after diet $\mathrm{M}$ followed by an increase after both diets $\mathrm{D}$ and $\mathrm{M}$ between 6 and $8 \mathrm{~h}$.

Fasting and $4 \mathrm{~h}$ postprandial fatty acid compositions of plasma total triacylglycerol samples are presented in Table 4 (data after 2, 6, and $8 \mathrm{~h}$ not shown). Values after $4 \mathrm{~h}$ reflected dietary fatty acid compositions with a lower plasma palmitic acid (16:0) concentration and a higher concentration of plasma stearic $(18: 0)$, oleic $(18: 1 n-9$, cis $)$ and trans fatty acids (mainly $18: 1 n-7$, trans and $18: 1 n-8$, trans) after the $\mathrm{M}$ fat. In addition, conjugated linoleic acid was higher after $M$ fat. Fasting values also mirrored the fatty acid composition of the test fats, but to a somewhat lesser degree.

\section{Discussion}

The aim of the present study was to investigate the effect of haemostatic variables of a modified, presumably less thrombogenic milk fat in a group of healthy young men. The modification of the milk fat was achieved by an alternative herd-feeding strategy leading to the replacement of palmitic acid with oleic acid as the major change. After 4 weeks' dietary intervention, we observed no differences in haemostatic variables (fasting values) between subjects consuming

Table 3. Fasting plasma triacylglycerol levels and concentrations of haemostatic variables in healthy male subjects consuming their habitual diet or diets containing modified milk fat (diet M) or conventional Danish milk fat (diet D) for 4 weeks

(Median values and ranges for eighteen subjects)

\begin{tabular}{|c|c|c|c|c|c|c|}
\hline & \multicolumn{2}{|c|}{ Habitual diet } & \multicolumn{2}{|c|}{ Diet D } & \multicolumn{2}{|c|}{ Diet M } \\
\hline & Median & Range & Median & Range & Median & Range \\
\hline FVIIc (\%) & 86 & $54-108$ & 81 & 54-98 & 83 & $51-104$ \\
\hline t-PA activity (IU/I) & 0.49 & $0.1-0.96$ & 0.54 & $0.24-1.20$ & 0.59 & $0.10-0.99$ \\
\hline PAI- 1 antigen $(\mu \mathrm{g} / \mathrm{l})$ & 12 & $3-33$ & 7 & $2-26$ & 8 & $2-20$ \\
\hline$\beta$-Thromboglobulin (IU/ml) & 22 & 11-33 & 22 & 11-33 & 24 & $12-47$ \\
\hline Fibrinogen $(\mu \mathrm{mol} / \mathrm{l})$ & 4.90 & $3.58-7.73$ & 4.77 & $3.92-6.74$ & 4.77 & $3.39-7.48$ \\
\hline Triacylglycerolł $(\mathrm{mmol} / \mathrm{l})$ & 0.85 & (SE 0.06) & 0.85 & (SE 0.07) & $0.99^{*}$ & (SE 0.09) \\
\hline
\end{tabular}

FVIIc, factor VII coagulant; t-PA, tissue plasminogen activator; PAI-1, plasminogen activator inhibitor type 1.

Mean value was significantly different from those for habitual diet and diet $D:{ }^{*} P=0.008$.

†For details of diets and procedures, see pp. 106-108.

$\ddagger$ Mean values with their standard errors. 
(a)

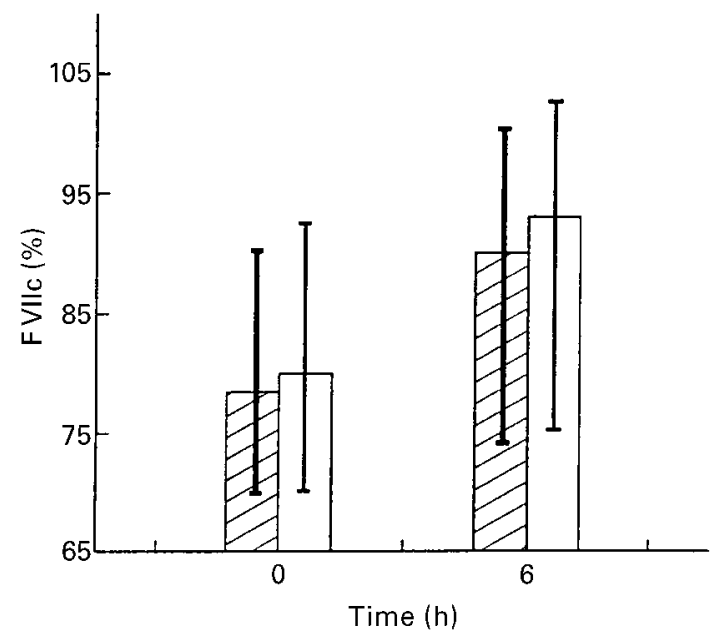

(b)

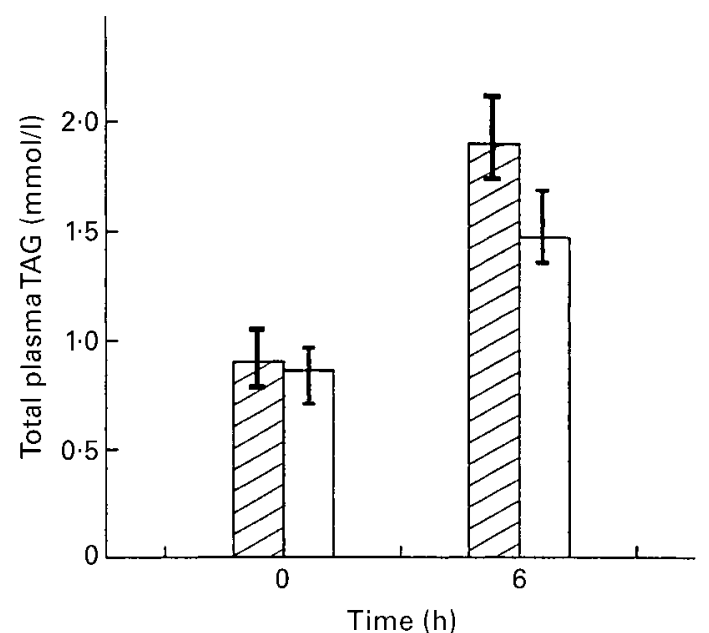

Fig. 1. (a) Plasma factor VII coagulant (FVIIc) and (b) plasma triacylglycerol (TAG) levels of healthy male subjects ( $n$ 18) consuming a diet containing modified milk fat $(\mathbb{Q})$ or a diet containing conventional Danish milk fat ( $\square$ ). Samples were taken on day 21 of the intervention and were collected after an overnight fast $(0 \mathrm{~h})$ or after intake of breakfast and lunch $(6 \mathrm{~h})$. Values for FVIlc are medians with $25-75$ percentile ranges indicated by vertical bars; values for TAG are means with their standard errors represented by vertical bars.

modified and conventional milk fats. Both fats were associated with postprandial increases in plasma FVIIc concentration, but postprandial FVIIc was marginally lower after the modified milk fat when consumed in large amounts as part of a test meal. Although this difference was small, it was contrary to what would be expected from the postprandial triacylglycerol response which was more pronounced after the modified milk fat (Tholstrup et al. 1998).

The herd-feeding regimen applied aimed at the production of a milk fat with less palmitic and myristic acids and more oleic and stearic acids. We did not quite obtain the planned differences, as we had to alter the original feeding regimen slightly. The reason was that the yield of the cows decreased when the feed content of unsaturated fatty acids became too high. However, as the modified feeding regimen could be implemented without any extra costs compared with conventional Danish feeding procedures, we considered it important to explore whether a realistically modified milk fat would be more beneficial in regard to risk factors for CHD than typical Danish milk fat.

Intake of diet $\mathrm{M}$ for 4 weeks did not result in a lower fasting FVIIc concentration compared with intake of conventional milk fat (D). Our expectation was that FVIIc would be lowered by diet $M$ because fasting FVIIc concentration was markedly reduced by a high stearic acid test fat (shea fat) as compared with test fats high in either palmitic acid or a combination of myristic and lauric acids in an earlier trial (Tholstrup et al. 1994a). It is possible that the differences in fatty acid compositions of diets $\mathrm{M}$ and $\mathrm{D}$ might not have been sufficient to cause differences in FVIIc response. Alternatively the shea fat might have affected FVIIc concentrations due to constituents other than fatty acids. However, the results of the present study support the findings of most other studies (Marckmann et al. 1990; Almendingen et al. 1996; Mutanen \& Aro, 1997) suggesting that the fatty acid composition of the diet has no effect on fasting FVIIc concentrations.
Postprandial elevations of FVIIc were seen with both test fats, which agrees with observations from several other trials (Salomaa et al. 1993; Bladbjerg et al. 1994; Silveira et al. 1994, 1996). However, diet M tended to cause lower postprandial FVIIc levels than diet D, and the marginal difference was significant when the modified fat was consumed in large amounts in a test meal. The effects of the diet on postprandial triacylglycerol levels were opposite with a significantly higher peak after diet $M$ than after diet $D$. This observation contrasts with a common opinion that postprandial FVIIc and triacylglycerol responses are very tightly linked (Salomaa et al. 1993; Silveira et al. 1994; Freese \& Mutanen, 1995). A dissociation of postprandial FVIIc and triacylglycerol responses has been reported in some other recent papers (Larsen et al. 1997; Marckmann et al. 1997), and it seems justified to reconsider the understanding of how FVIIc and triacylglycerol interact. We speculate that the FVIIc-triacylglycerol link may be modified by the fatty acid composition of cell membranes involved in activation of FVII. In our study, the postprandial measurements were made after several weeks of dietary intervention with fats of different fatty acid composition. Consequently the cell membrane fatty acid compositions as indicated by the differences in fasting plasma lipid fatty acid composition were not the same after diets $M$ and $D$.

The triacylglycerol increasing effect of trans fatty acid observed in this study, consistent with findings by others (Anderson et al. 1961; Mensink \& Katan, 1990; Wood et al. 1993; Judd et al. 1994), has been discussed previously (Tholstrup et al. 1998).

The two milk fats did not affect fasting t-PA activity and PAI-1 antigen differently which agrees with previous findings (Tholstrup et al. 1994a,b; Mutanen \& Aro, 1997). One study reported an increased antifibrinolytic effect of trans fatty acids (from partially hydrogenated soyabean oil) compared with partially hydrogenated fish oil and butter fat (Almendingen et al. 1996). Our fats (M and D) had different 
(a)

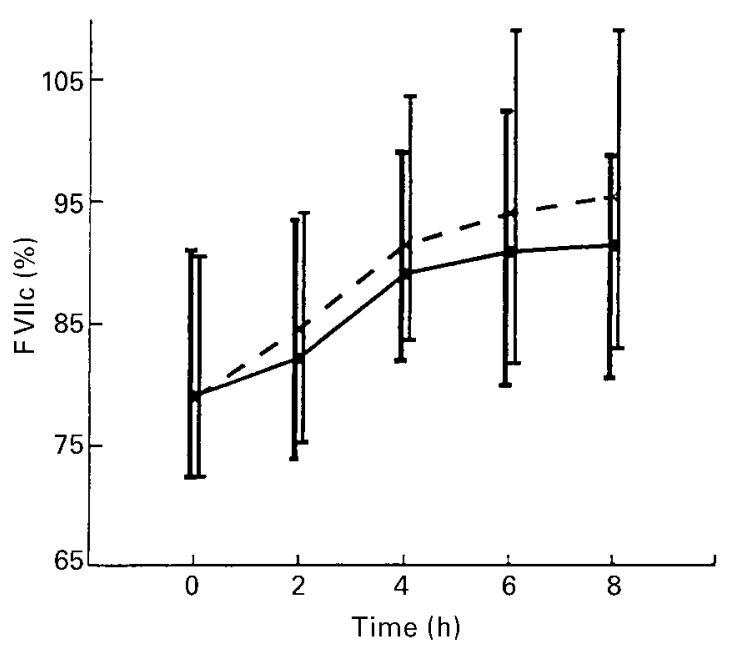

(c)

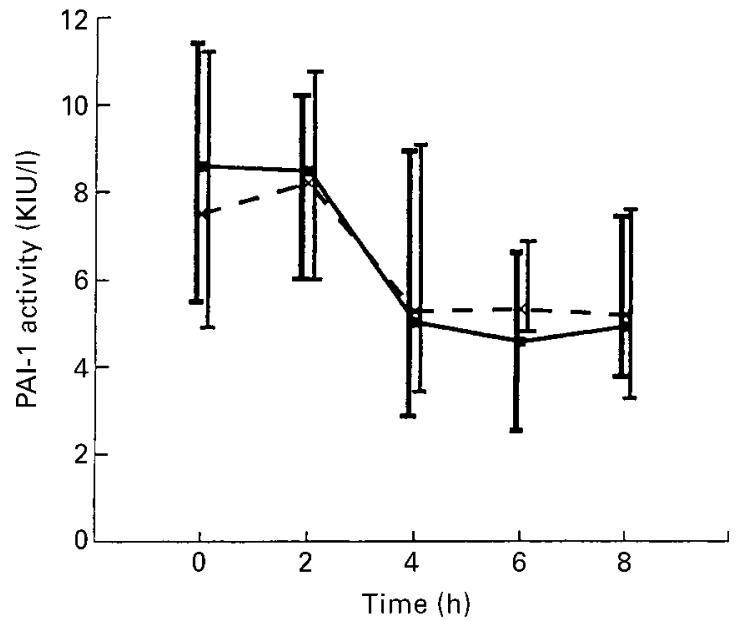

(e) (b)

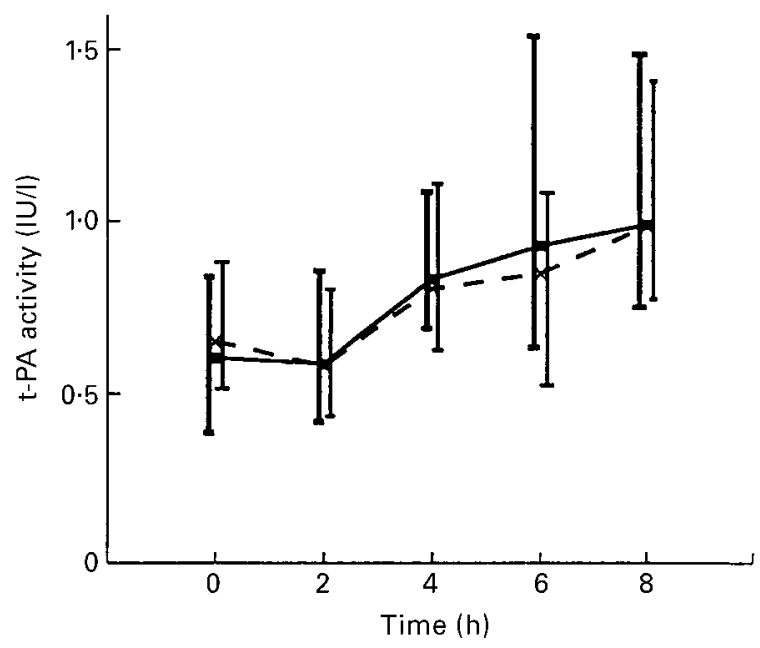

(d)

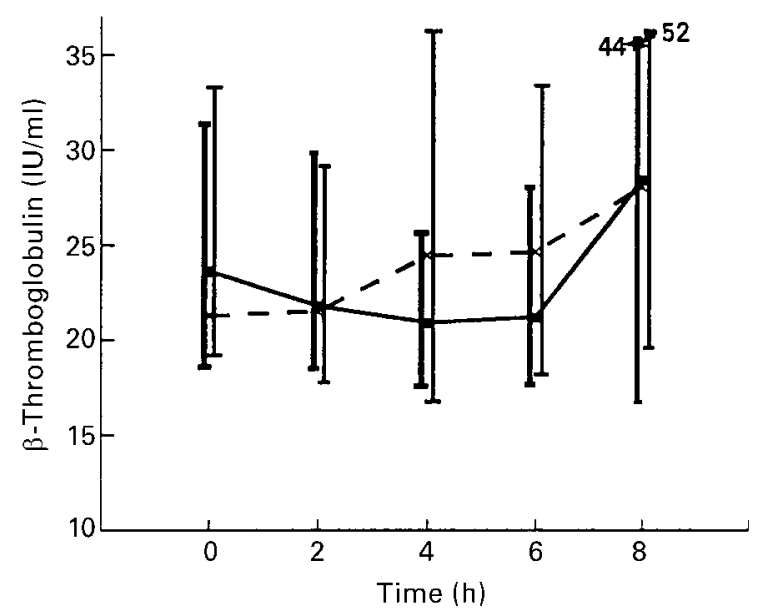

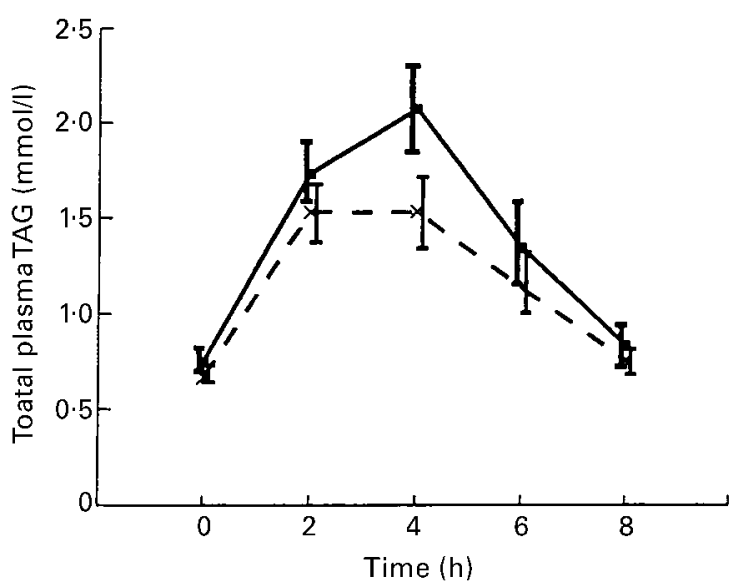

Fig. 2. (a) Factor VII coagulant (FVIIc) activity, (b) tissue plasminogen activator (t-PA) activity, (c) plasminogen activator inhibitor type 1 (PAl-1) activity, (d) $\beta$-thromboglobulin level and (e) total plasma triacylglycerol (TAG) level in healthy male subjects before ( $0 \mathrm{~h}$ ) and after consumption of fat loads $(1.2 \mathrm{~g}$ milk fat $/ \mathrm{kg}$ body weight) of different composition. The fat load was consumed immediately after the baseline blood sample was taken and consisted of either modified milk fat (--) or conventional Danish milk fat (--X--). For details of diets and procedures, see pp. 106-108. 
Table 4. Fatty acid composition ( $\mathrm{g} / 100 \mathrm{~g}$ total fatty acids) of the plasma total triacylglycerols of healthy male subjects before $(0 \mathrm{~h})$ and $4 \mathrm{~h}$ after a fat load consisting of modified milk fat (diet M) or conventional Danish milk fat (diet D) $\dagger$

(Mean values with their standard errors for eight subjects)

\begin{tabular}{|c|c|c|c|c|c|c|c|c|}
\hline \multirow[b]{3}{*}{ Fatty acid } & \multicolumn{4}{|c|}{$\mathrm{Oh}$} & \multicolumn{4}{|c|}{$4 \mathrm{~h}$} \\
\hline & \multicolumn{2}{|c|}{ Diet M } & \multicolumn{2}{|c|}{ Diet D } & \multicolumn{2}{|c|}{ Diet M } & \multicolumn{2}{|c|}{ Diet D } \\
\hline & Mean & SE & Mean & SE & Mean & SE & Mean & SE \\
\hline $12: 0$ & 0.16 & 0.02 & 0.21 & 0.03 & 0.63 & 0.05 & 0.85 & 0.11 \\
\hline $14: 0$ & 2.03 & 0.19 & 1.98 & 0.25 & 5.78 & 0.29 & $6 \cdot 10$ & 0.48 \\
\hline $14: 1$ & 0.25 & 0.02 & 0.32 & 0.05 & 0.99 & 0.06 & 1.04 & 0.08 \\
\hline 15:0‡ & 0.50 & 0.04 & 0.51 & 0.04 & $0.65^{\star \star \star}$ & 0.02 & 0.85 & 0.04 \\
\hline 16:0‡ & $20 \cdot 44^{\star \star *}$ & 0.53 & 24.91 & 0.38 & $22.59^{\star \star \star *}$ & 0.27 & 34.19 & 0.67 \\
\hline $16: 1 n-7$ & $2.68^{* * *}$ & 0.17 & 3.15 & 0.22 & $2 \cdot 31^{\text {***}}$ & 0.06 & 3.09 & 0.12 \\
\hline 17:0‡ & $0.32^{*}$ & 0.02 & 0.39 & 0.03 & $0.40^{* * *}$ & 0.01 & 0.58 & 0.02 \\
\hline $17: 1$ & $0.25^{\star \star}$ & 0.01 & 0.32 & 0.02 & $0.22^{\star \star *}$ & 0.00 & 0.30 & 0.01 \\
\hline $18: 0$ & 3.72 & 0.21 & 3.62 & 0.18 & $8 \cdot 25^{\star \star *}$ & 0.30 & 5.77 & 0.18 \\
\hline $18: 1$, trans & $1.55^{\star * *}$ & 0.13 & 0.50 & 0.05 & $3.52^{\star * *}$ & 0.19 & 0.69 & 0.15 \\
\hline $18: 1 n-9$ & $34.05^{\star}$ & 0.88 & 30.89 & 1.20 & $32.91^{\star \star}$ & 0.68 & 25.88 & 1.01 \\
\hline $18: 1 n-7$ & 2.47 & 0.09 & $2 \cdot 41$ & 0.13 & $2.03^{\text {** }}$ & 0.06 & 1.67 & 0.12 \\
\hline $18: 2 n-6$ & 21.41 & $10 \cdot 12$ & 21.28 & 0.73 & $10 \cdot 66^{\star \star}$ & 0.63 & 11.73 & 0.65 \\
\hline $18: 3 n-6$ & 0.29 & 0.05 & 0.27 & 0.04 & 0.14 & 0.03 & 0.16 & 0.03 \\
\hline $20: 0$ & $0.91^{*}$ & 0.03 & 0.97 & 0.04 & $0.90^{*}$ & 0.01 & 0.81 & 0.03 \\
\hline Conjugated $18: 2 \S$ & $0.85^{\star * *}$ & 0.03 & 0.46 & 0.02 & $1 \cdot 12^{\star \star *}$ & 0.05 & 0.48 & 0.01 \\
\hline
\end{tabular}

Mean values were significantly different from those for diet $D:{ }^{*} P<0.05,{ }^{* *} P<0.01,{ }^{* * *} P<0.001$.

†For details of diets and procedures, see pp. 106-108.

$\ddagger 15: 0,16: 0$ and 17:0 also included the branched isoforms typical of milk fat.

$\S$ Conjugated $18: 2$ also included $20: 0(0.20-0.25 \mathrm{~g} / 100 \mathrm{~g}$ total fatty acids).

contents of trans fatty acids. The absence of an effect on PAI-1 antigen could be due to the absolute content of trans fatty acid in $M$ and $D$ being too small, or it could be that trans fatty acids of milk fat (mainly vaccenic acid) and hydrogenated soyabean oil (mainly elaidic acid) affect PAI-1 differently. From fasting values, t-PA activity increased and PAI-1 antigen and activity decreased after food intake, which is consistent with earlier observations (Andreotti et al. 1988; Marckmann et al. 1992a, 1993a).

The lack of effect of dietary fatty acid composition on non-fasting plasma fibrinogen after the study periods, is in accordance with other results from our department (Marckmann et al. 1991, 1993b, 1994). However, we (Bladbjerg et al. 1995), and others (Mutanen \& Aro, 1997) have previously found a slightly increasing effect of stearic-acid-rich test fat on fibrinogen. Probably the change in stearic acid was too small to affect fibrinogen. Although there is a strong association between fibrinogen and risk of CHD (Smith, 1986; Bijnen et al. 1996), diet does not seem to play a major role, whereas changes in smoking and BMI are known to influence fibrinogen (Bijnen et al. 1996).

Conflicting results have been reported from studies including measurements of in vitro platelet aggregability during postprandial hyperlipidaemia. Some studies report an increase in platelet aggregation (Johnston et al. 1982; Fuhrman et al. 1986; Bisovsky et al. 1992), whereas we (Tholstrup et al. 1996) and others observed a decrease in platelet aggregation after a fat load (Nimpf et al. 1989; Freese \& Mutanen, 1995). Due to the difficulties in interpretation of platelet aggregation as a predictor of in vivo behaviour (Bisovsky et al. 1992), we measured release of the platelet-specific protein $\beta$-thromboglobulin as it is considered to be a valid, indirect method of evaluating in vivo behaviour of platelets (Dawes et al. 1978). Fasting plasma $\beta$-thromboglobulin was not affected differently by the two milk fats, which corresponds with findings from others (Almendingen et al. 1996), but disagrees with a single study (Sanders et al. 1997). The milk-fat load showed an effect over time on $\beta$-thromboglobulin with an increase in $\beta$-thromboglobulin levels between 6 and $8 \mathrm{~h}$ after both fats. Previous studies by us and others have shown ambiguous results with a minor tendency towards an increase in non-fasting $\beta$-thromboglobulin level after intake of some test fats, but not after others (Salomaa et al. 1993; Tholstrup et al. 1996). However, due to the very few dietary experiments including $\beta$-thromboglobulin the picture of the effects of dietary fat on $\beta$-thromboglobulin is unclear.

The intake of milk fat (M) high in oleic acid and low in palmitic acid resulted in slightly lower postprandial FVIIc concentrations as compared with conventional milk fat (D) high in palmitic acid and low in oleic acid. The difference was only marginal and the biological significance is dubious. In addition, fasting and postprandial plasma total triacylglycerol levels were elevated by $\operatorname{diet} \mathrm{M}$, which may be due to its higher trans fatty acid content. Results from this study combined with studies by others suggest that dietary fatty acid composition does not play a major role in determining fasting plasma concentrations and activities of haemostatic variables, but that dietary fatty acid composition of the habitual diet can slightly modify postprandial FVII responses.

We conclude that the tested milk fat enriched with oleic acid by way of a realistic change of herd feed had virtually the same thrombogenic characteristics as conventional milk fat. 


\section{Acknowledgements}

We thank dietitian Hanne Jensen, Ingerlise Grönfeldt and the other staff of the metabolic kitchen. We thank Pia Lund, MSc for the GC analysis and our laboratory technicians Kirsten Ebbesen and Klara Jörgensen, for their conscientious and excellent work. Supported by grant JD-93 S 2464 A99300085, The Danish Research Development Program for Food Technology (FOETEK).

\section{References}

Almendingen K, Seljeflot I, Sandstad B \& Pederson JI (1996) Effects of partially hydrogenated fish oil, partially hydrogenated soybean oil, and butter on hemostatic variables in men. Arteriosclerosis, Thrombosis and Vascular Biology 16, 375380.

Anderson JT, Grande F \& Keys A (1961) Hydrogenated fats in the diet and lipids in the serum of man. Journal of Nutrition $\mathbf{7 5}$, 388-394.

Andreotti F, Davies GJ, Hackett DR, Khan MI, De Bart ACW, Aber VR, Maseri A \& Kluft C (1988) Major circadian fluctuations in fibrinolytic factors and possible relevance to time of onset of myocardial infarction, sudden cardiac death and stroke. American Journal of Cardiology 62, 635-637.

Bijnen FCH, Feskens EJM, Giampaoli S, Menotti A, Fidanza F, Hornstra G, Caspersen CJ, Mosterd WL \& Kromhout D (1996) Haemostatic parameters and lifestyle factors in elderly men in Italy and The Netherlands. Thrombosis and Haemostasis 76, 411-416.

Bisovsky S, Richter H, Fitscha P, O’Grady J \& Sinzinger H (1992) Postprandial hyperlipemia does not inhibit platelet aggregation. Prostaglandins Leukotrienes and Essential Fatty Acids 47, 331332.

Bladbjerg EM, Marckmann P, Sandström B \& Jespersen J (1994) Non-fasting factor I coagulant activity (FVII:C) increased by high-fat diet. Thrombosis and Haemostasis 71, 755-758.

Bladbjerg EM, Tholstrup T, Marckmann P, Sandström B \& Jespersen J (1995) Dietary changes in fasting levels of factor VII coagulant activity (FVII:C) accompanied by changes in factor VII protein and other vitamin $\mathrm{K}$-dependent proteins. Thrombosis and Haemostasis 73, 239-242.

Botti RE \& Ratnoff OD (1963) The clot-promoting effect of soaps of long-chain saturated fatty acids. Journal of Clinical Investigation 42, 1569-1577.

Bysted A, Hølmer G \& Lund P (1998) Influence of moderate amounts of trans fatty acids on the formation of polyunsaturated fatty acids. Journal of the American Oil Chemists Society 75, 225-234.

Connor W (1962) The acceleration of thrombus formation by certain fatty acids. Journal of Clinical Investigation 41, 1199-1205.

Connor WE \& Poole JCF (1961) The effect of fatty acids on the formation of thrombi. Quarterly Journal of Experimental Physiology 46, 1-7.

Dawes J, Smith RC \& Pepper DS (1978) The release, distribution, and clearance of human $\beta$-thromboglobulin and platelet factor 4 . Thrombosis Research 12, 851-861.

Freese R \& Mutanen M (1995) Postprandial changes in platelet function and coagulation factors after high-fat meals with different fatty acid compositions. European Journal of Clinical Nutrition 49, 658-664.

Fuhrman B, Brook JG \& Aviram M (1986) Increased platelet aggregation during alimentary hyperlipemia in normal and hypertriglyceridemic subjects. Annals of Nutrition and Metabolism 30, 250-260.

Gram J, Declerck PJ, Jespersen J \& Kluft C (1993) Multicentre evaluation of commercial kit methods: plasminogen activator inhibitor activity. Thrombosis and Haemostasis 70, 852-857.

Hermansen JE (1995) Prediction of milk fatty acid profile in dairy cows fed dietary fat differing in fatty acid composition. Journal of Dairy Science 78, 872-879.

Høy C-E \& Hølmer G (1988) Dietary linoleic acid and the fatty acid profiles in rats fed partially hydrogenated marine oils. Lipids 23, 973-980.

Johnston RV, Giner JV, Lowe GDO, Forbes CD \& Prentice CRM (1982) Prevention of lipid induced platelet aggregation by aspirin. Thrombosis Research 27, 235-239.

Judd JT, Clevidence BA, Muesing RA, Wittes J, Sunkin ME \& Podczasy JJ (1994) Dietary trans fatty acids: effects on plasma lipids and lipoproteins of healthy men and women. American Journal of Clinical Nutrition 59, 861-868.

Junker R, Heinrich J, Schulte H, van Loo J \& Assman G (1997) Coagulation factor VII and the risk of coronary heart disease in healthy men. Arteriosclerosis, Thrombosis and Vascular Biology 17, 1539-1544.

Larsen LF, Bladbjerg EM, Jespersen J \& Marckmann P (1997) Effects of dietary fat quality and quantity on postprandial activation of blood coagulation factor VII. Arteriosclerosis, Thrombosis and Vascular Biology 17, 2904-2909.

Marckmann P, Bladbjerg EM \& Jespersen J (1997) Dietary fish oil ( $4 \mathrm{~g}$ daily) and cardiovascular risk markers in healthy men. Arteriosclerosis, Thrombosis and Vascular Biology 17, 33843391.

Marckmann P, Jespersen J, Leth T \& Sandström B (1991) Effect of fish diet versus meat diet on blood lipids, coagulation and fibrinolysis in healthy young men. Journal of Internal Medicine 229, 317-323.

Marckmann P, Jespersen J \& Sandström B (1992a) Dietary $n-3$ and $n-6$ polyunsaturated fatty acids affect the fibrinolytic system differently. In Essential Fatty Acids and Eicosanoids. Invited Papers from the Third International Congress, pp. 325-329 [A Sinclair and R Gibson, editors]. Champaign, IL: American Oil Chemists' Society.

Marckmann P, Sandström B \& Jespersen J (1990) Effects of total fat content and fatty acid composition in diet on factor VII coagulant activity and blood lipids. Atherosclerosis 80, 227-233.

Marckmann P, Sandström B \& Jespersen J (1992b) Fasting blood coagulation and fibrinolysis of young adults unchanged by reduction in dietary fat content. Arteriosclerosis and Thrombosis 12, 201-205.

Marckmann P, Sandström B \& Jespersen J (1993a) Dietary effects on circadian fluctuation in human blood coagulation factor VII and fibrinolysis. Atherosclerosis 101, 225-234.

Marckmann P, Sandström B \& Jespersen J (1993b) Favorable long-term effect of a low-fat/high-fiber diet on human blood coagulation and fibrinolysis. Arteriosclerosis and Thrombosis 13, 505-511.

Marckmann P, Sandström B \& Jespersen J (1994) Low-fat highfiber diet favorably affects several independent risk markers of ischemic heart disease. Observations on blood lipids, coagulation, and fibrinolysis from a trial of middle-aged Danes. American Journal of Clinical Nutrition 59, 935-939.

Meade TW, Ruddock V, Stirling Y, Chakrabarti R \& Miller GJ (1993) Fibrinolytic activity, clotting factors, and long-term incidence of ischaemic heart disease in the Northwick Park Heart Study. Lancet 342, 1076-1079.

Mensink RP \& Katan MB (1990) Effect of dietary trans fatty acids on high-density and low-density lipoprotein cholesterol levels in healthy subjects. New England Journal of Medicine 323, 439445.

Miller GJ, Martin JC, Mitropoulos KA, Esnouf MP, Cooper JA, Morrissey JH, Howarth DJ \& Tuddenham EGD (1996) Activation of factor VII during alimentary lipemia occurs in healthy 
adults and patients with congenital factor XII or factor XI deficiency, but not in patients with factor IX deficiency. Blood 87, 4187-4196.

Mutanen M \& Aro A (1997) Coagulation and fibrinolysis factors in healthy subjects consuming high stearic or trans fatty acid diets. Thrombosis and Haemostasis 77, 99-104.

Nimpf J, Malle E, Leopold B, Wurm H \& Kostner GM (1989) Postprandial hyperlipemia inhibits platelet aggregation without affecting prostanoid metabolism. Prostaglandins Leukotrienes and Essential Fatty Acids 37, 7-13.

Nord $\varnothing$ y A \& Goodnight SH (1990) Dietary lipids and thrombosis. Relationships to atherosclerosis. Atherosclerosis 10, 149-163.

Salomaa V, Rasi V, Pekkanen J, Jauhiainen M, Vahtera E, Pietinen P, Korhonen H, Kuulasmaa K \& Ehnholm C (1993) The effects of saturated fat and $n-6$ polyunsaturated fat on postprandial lipemia and hemostatic activity. Atherosclerosis 103, 1-11.

Sanders TAB, Oakley FR, Miller GJ, Mitropoulos KA, Crook D \& Oliver MF (1997) Influence of $n-6$ versus $n-3$ polyunsaturated fatty acids in diets low in saturated fatty acids on plasma lipoproteins and hemostatic factors. Arteriosclerosis, Thrombosis and Vascular Biology 17, 3449-3460.

Silveira A, Karpe F, Blombäck M, Steiner G, Walldius G \& Hamsten A (1994) Activation of coagulation factor VII during alimentary lipemia. Arteriosclerosis and Thrombosis 14, 60-69.

Silveira A, Karpe F, Johnsson H, Bauer KA \& Hamsten A (1996) In vivo demonstration in humans that large postprandial triglyceride-rich lipoproteins activate coagulation factor VII through the intrinsic coagulation pathway. Arteriosclerosis, Thrombosis and Vascular Biology 16, 1333-1339.

Smith EB (1986) Fibrinogen, fibrin and fibrin degradation products in relation to atherosclerosis. Clinical Haematology 15, 355-370.
Takahashi H, Yoshino N \& Shibata A (1988) Measurement of platelet factor 4 and $\beta$-thromboglobulin by an enzyme-linked immunosorbent assay (letter). Clinica Chimica Acta 175, 113114.

Tholstrup T, Andreasen K \& Sandström B (1996) Acute effect of high-fat meals rich in either stearic or myristic acid on hemostatic factors in healthy young men. American Journal of Clinical Nutrition 64, 168-176.

Tholstrup T, Marckmann P, Jespersen J \& Sandström B (1994a) Fat high in stearic acid favorably affects blood lipids and factor VII coagulant activity in comparison with fats high in palmitic acid or high in myristic and lauric acids. American Journal of Clinical Nutrition 59, 371-377.

Tholstrup T, Marckmann P, Jespersen J, Vessby B, Jart Aa \& Sandström B (1994b) Effect on blood lipids, coagulation and fibrinolysis of a fat high in myristic acid and a fat high in palmitic acid. American Journal of Clinical Nutrition 60, 919925.

Tholstrup T, Sandström B, Hermansen JE \& Hølmer G (1998) Effect of modified dairy fat on postprandial and fasting plasma lipids and lipoproteins in healthy young men. Lipids 33, 1121.

Thomson JM (editor) (1985) Blood Coagulation and Haemostasis, A Practical Guide, 4th ed. New York: Churchill Livingstone.

Wood R, Kubena K, O’Brien B, Tseng S \& Martin G (1993) Effect of butter, mono- and polyunsaturated fatty acid-enriched butter, trans fatty acid margarine, and zero trans fatty acid margarine on serum lipids and lipoproteins in healthy men. Journal of Lipid Research 34, 1-11.

World Health Organization (1985) Energy and Protein Requirements. Technical Report Series no. 724. Geneva: WHO. 